\begin{tabular}{|l|c|c|}
\hline Volume 3, Number 20 & Research Question Review & 6 NOVEMBER 2019 \\
\hline
\end{tabular}

\title{
How can Complex Organizations Engage in a Successful Restructuring while Simultaneously Improving the Delivery of Products and Capabilities?
}

\author{
By \\ Patty LePage, University of Maryland Global Campus \\ Allyson Oliver-Jones, University of Maryland Global Campus \\ John Onyeaku, University of Maryland Global Campus \\ Remedious Bernadine Douglas, University of Maryland Global Campus \\ Denise Breckon, University of Maryland Global Campus
}

$\mathrm{O}$ rganizations continually face internal and external pressures that require them to change their structure. These restructures have the potential to spur organizational problems from employ ee churn, including a decrease in employee engagement as well as detract from product delivery. The purpose of this study is to systematically gather and review evidence on employee engagement and retention during organizational restructuring initiatives. Another purpose is to define how leadership style can impact the organization's ability to successfully restructure while also improving the efficiency and effectiveness of the ongoing products. An analysis was carried out using four rapid evidence assessments and then a combined systematic review to analyze existing scholarly literature on the research question.
The organizational problem was viewed through the lens of the contingency theory, which focuses on the structure best suited to the organization, contingent on its internal
A complex organization can impact a restructure by focusing on the processes and people behind it. Clear communication, an ambidextrous leadership style, training, and job resources can all contribute to maintaining employee engagement and the success of the restructuring initiative. and external environments. With a complex restructure, an organization can align with their internal mission, as well as their customers in the external environment. A thematic analysis of the literature revealed several themes: job resources, leadership styles, team innovation, training, external and internal environmental factors, employee engagement, open communication and organizational diagnosis. This study supports the notion that a successful restructure can be implemented through the support of an effective leadership style, training, and the implementation of job resources.

Keywords: Ambidextrous leader, employee engagement, rapid evidence assessment, reorganization, restructuring, systematic review

Copyright ( 2019, Patty LePage, Allyson Oliver-Jones, John Onyeaku, Remedious Bernadine Douglas e Denise Breckon This article is published under a Creative Commons BY-NC license. Permission is granted to copy and distribute this article for non-commercial purposes, in both printed and electronic formats 
Complex organizations operate in an industrial landscape that are demanding more from its entities. As a result, organizations have been challenged to create more agile and ambidextrous environments. These demands have generated opportunities that resulted in the need for organizational restructuring. The complexity of restructuring often does not emanate positively throughout the organizational culture, resulting in challenges with the implementation of the next level of readiness and commitment. Organizations hope to plan and implement the restructure while maintaining or improving their performance. The researchers are addressing this organizational problem using an exploratory evidence-based research approach.

The targeted organization provided an organizational problem which was used to form the research question; however, no actual field research was conducted. The organization is transitioning to a mission-aligned organization while being challenged to develop and deliver capabilities better and faster, focusing resources on ensuring availability, reliability, and maintenance of aircraft and weapons, improving mission readiness. The organization's restructure objectives are being impacted by the current structure, internal engineering culture, time frame to deploy, and current resources compared to workload. The current culture consists of competency communities, which have core teams within each working unit. The restructure will rebalance human capital resources, realigning personnel in direct support of missions and programs, which has senior leaders and employees worried about changing team structures and job loss.

Change management is always a challenge for organizations. Due to its military hierarchy, the organization has experienced frequent changes in its command structure. With each change of command comes new organizational change. This high frequency of change contributes to employees resisting transformation. The current commander's mission-aligned focus has necessitated a change in the organizational culture. Employees are resistant due to the perceived threat to their positional authority. The current competency-aligned culture recognizes engineering teams as perhaps the most important units within the organization. The shift to a mission-aligned structure disrupts the current culture. This study takes a current organizational problem and relies on data from theory and existing research to provide recommendations to the organization. The research question for this study is: How can complex organizations engage in a successful restructuring while simultaneously improving the delivery of products and capabilities?

The literature on organizational restructuring and employee responses were analyzed through a theoretical lens to inform the research problem and answer the research question.

\section{Literature Summary}

The summary of the included literature is presented by theme in Table 1 .

Restructuring has been found to have negative effects on overall employee health and stress levels (Mathisen, Brønnick, Arntzen, \& Bergh, 2017; Spremo \& Prodanović, 2013). Unless circumstances were mitigated to reduce the effects, restructuring had a strong negative impact on employee's well-being, regardless of layoffs. It is important for

\section{Methodology}

The organizational study enlisted a systematic review of the recent empirical literature on organizational restructuring. Gough, Oliver, and Thomas (2017) define systematic review as "a review of existing research using explicit, accountable, rigorous research methods" (p. 2). A systematic review involved a comprehensive search for evidence to explore what is known about the research question as well as what is not known. The systematic review was formed from four individual Rapid Evidence Assessments (REA) (Briner et al., 2009). The REA provides a quick and narrowly scoped review that contributes evidence to the broader research question. Four researchers conducted the REAs simultaneously based on four individual research questions developed based on the target organization's restructure: (1) What is known in the scientific literature about maintaining or improving employee engagement and retention during organizational restructuring initiatives? (2) How do leadership theories impact complex organizations' ability to successfully restructure while maintaining their ambidextrous capabilities? (3) How can evidence-based tools help a large, complex organization successfully implement restructuring to become more agile while operating under strict deadlines to deliver quality products and services? and (4) How can a complex organization successfully streamline processes and workloads to better align with their mission?

Memoing techniques were used to record the operational, coding and analytical processes throughout the systematic review, which allowed the researchers to engage deeply into the data, while maintaining continuity in the analysis (Birks, Chapman, \& Francis, 2008). Memoing involves recording key words, phrases, and concepts. This method was used to extract common themes using codes from the four REAs. ATLAS.ti and Dedoose, qualitative analysis coding tools, were used to code the literature (ATLAS.ti, 2019). Each article was coded by two individuals to support rigor and transparency in the research.. 
The comprehensive search strategy began with well-developed search strings. The following search strings were used during the literature search for the four individual REAs:

1. Using OneSearch and ProQuest databases:

("employee engagement" AND "reorganization") ("employee retention" AND "reorganization") AND ("employee engagement" AND "organizational restructure") AND ("employee retention" AND "organizational restructure")

2. Using EbscoHost and Business Source Complete databases, two search strings were used:

a. (reorg* OR restructur*) n10 (employee* OR staff* OR workforce OR worker* OR personnel) n10 (buy-in OR accept* OR embrac* OR support* OR resist* OR fight* OR oppos*) AND communicat*

\section{b. Leadership AND management AND restructuring OR reorganization}

3. Using EBSCO database:

("evidence-based management" OR evidence-based practice") AND (restructur* OR reorganiz* OR "organizational change") AND ("large and complex corporation" OR organization).

Using ProQuest database:

(organizational change) AND (organizational restructuring)

4. Using OneSearch database and the Academy of Management website:

(business or company) AND restructur* AND (improve or streamline)

Combining the articles from the search strings of the four REAs resulted in over 903 articles through OneSearch, EBSCO, Business One Source, and ProQuest databases and the Academy of Management website. After duplicates were removed, the total was 419. The titles and abstracts of these 419 articles were reviewed and those that did not meet the inclusion criteria were excluded. The 242 articles remaining were screened for relevance in answering the research question, and 161 were excluded as they did not appear to provide evidence for this study. The first level of inclusion was that the evidence retrieved should include empirical research studies. Additional criteria included the exclusion of those published in any languages other than English. This was to ensure that the findings were relevant to our organization. Although the four original REAs did not use standard exclusion criteria, the final set of articles were reviewed to ensure that they provided evidence to answer this study's research question. A full text read and review were done on the 81 remaining articles with 43 excluded with reason. Ultimately, 38 articles were maintained for this study.

A critical evaluation of these 38 articles was conducted using the TAPUPAS method developed by Pawson, Boaz, Grayson, Long, and Barnes (2003). The appraisal for TAPUPAS includes the following criteria: transparency, accuracy, purposivity, utility, propriety, accessibility, and specificity (Pawson et al., 2003). Each item was assessed on a scale of 1-3 to indicate low to high quality, and an average score was assigned. Seven of the 38 articles were scored between 1.0- 2.0 indicating that some of the criteria were either not met or not addressed, but the flaws did not appear to compromise the evidence. All the articles were kept in the analysis, and although not all articles were included in the primary findings, they added value to the discussion. The 38 articles left for inclusion in the study were coded to develop themes and patterns during the thematic analysis. The findings from the review articles were synthesized into five themes.

organizations to plan to mitigate psychosocial risks during the restructuring. Failure to plan and implement supportive programs can lead to the failure of change initiatives. Several common themes were identified consistently in the literature, including job insecurity, communication, organizational trust, employee engagement, job resources, leadership, training, and organizational diagnosis. These common themes were further broken down into the following five overarching themes relevant to the organizational problem.

\section{Theoretical Lens}

The research question of how complex organizations can engage in a successful restructuring while simultaneously improving the delivery of products and capabilities was addressed through the lens of contingency theory. Contingency theory focuses on finding the structure that best fits the organization, contingent on its internal and external environments (McKinley \& Scherer, 2000).

The organizational problem was viewed through multiple theoretical lenses to determine the best fit 
Table 1. Themes for a Successful Organizational Restructure

\begin{tabular}{|c|c|c|}
\hline Theme & Findings from the Literature & References \\
\hline \multirow{2}{*}{$\begin{array}{l}\text { Job Resources } \\
\text { Effective job resources result } \\
\text { in better-in-role task perfor- } \\
\text { mance, better team level per- } \\
\text { formance, higher financial } \\
\text { returns, customer satisfaction, } \\
\text { and positive attitudes toward } \\
\text { the organization forming strong } \\
\text { organizational commitment. }\end{array}$} & $\begin{array}{l}\text { Job resources such as supportive leadership, } \\
\text { job control, and performance feedback can } \\
\text { assist in providing clarity and structure to } \\
\text { newly developed strategies and mission at- } \\
\text { tributes. }\end{array}$ & $\begin{array}{l}\text { O’Reilly \& Tushman, } \\
\text { 2011; Seppälä, Hakanen, } \\
\text { Tolvanen, \& Demerou- } \\
\text { ti, 2018; Havermans, } \\
\text { Den Hartog, Keegan, \& } \\
\text { Uhl-Bien, 2015 } \\
\end{array}$ \\
\hline & $\begin{array}{l}\text { Job resources aid employees in developing } \\
\text { team innovation by articulating a clear vi- } \\
\text { sion. }\end{array}$ & $\begin{array}{l}\text { Christian, Garza, \& } \\
\text { Slaughter, 2011; Schaufe- } \\
\text { li, Bakker, \& Van Rhenen, } \\
\text { 2003; Anderson, } 2017\end{array}$ \\
\hline \multirow{2}{*}{$\begin{array}{l}\text { Leadership and Team Innova- } \\
\text { tion } \\
\text { The ambidextrous leader man- } \\
\text { ages the tensions between ex- } \\
\text { ploration and exploitation, as } \\
\text { well as the balance between } \\
\text { the need to innovate and the } \\
\text { need to produce. This balance } \\
\text { enables the leader to guide fol- } \\
\text { lowers towards well focused } \\
\text { outcomes, creating competitive } \\
\text { advantage out of the conflict- } \\
\text { ing forces. }\end{array}$} & $\begin{array}{l}\text { Ambidextrous leadership was supported by } \\
\text { the literature as effectively addressing the } \\
\text { organizational tension and maintaining bal- } \\
\text { ance between the organizational change ef- } \\
\text { forts and an increase in productivity. }\end{array}$ & $\begin{array}{l}\text { Rosing, Freses, \& Baus- } \\
\text { ch, 2011; Lin \& Yoo, } \\
\text { 2013; Gibson, } 2011\end{array}$ \\
\hline & $\begin{array}{l}\text { Ambidextrous leadership theory proposes } \\
\text { the interaction between two complementary } \\
\text { leadership behaviors - opening and closing } \\
\text { - predict team innovation. Team innovation } \\
\text { is highest when both opening and closing } \\
\text { leadership behaviors are high, resulting in } \\
\text { high adaptability and team outcomes. }\end{array}$ & $\begin{array}{l}\text { Bakari, Hunjra, \& Niazi, } \\
\text { 2017; Uhl-Bien \& Arena, } \\
2018\end{array}$ \\
\hline \multirow{3}{*}{$\begin{array}{l}\text { Training } \\
\text { The development of suitable } \\
\text { training programs can ensure } \\
\text { employees and leaders are bet- } \\
\text { ter able to understand the bene- } \\
\text { fits of restructure and therefore } \\
\text { be open to change. }\end{array}$} & $\begin{array}{l}\text { Employees need the ability to develop skills } \\
\text { through training programs, allowing them to } \\
\text { meet greater challenges. }\end{array}$ & $\begin{array}{l}\text { Mathisen et al., 2017; } \\
\text { Plimmer, Bryson, \& } \\
\text { Theo, 2017; Sy, Horton, } \\
\text { \& Riggio, 2018 } \\
\end{array}$ \\
\hline & $\begin{array}{l}\text { The literature supported training programs } \\
(87.5 \%) \text { as positively linked to reducing } \\
\text { job strain during restructuring. Training for } \\
\text { managers supports communication of the } \\
\text { new mission and strategy. }\end{array}$ & $\begin{array}{l}\text { Pérez la Rotta, \& Campos } \\
\text { Herrera, } 2011\end{array}$ \\
\hline & $\begin{array}{l}\text { Targeted training for employees, consisting } \\
\text { of developing changes to job work process- } \\
\text { es and innovation, can increase job security } \\
\text { and engagement while improving skills. }\end{array}$ & 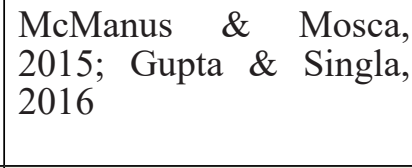 \\
\hline \multirow[t]{3}{*}{$\begin{array}{l}\text { Employee Engagement and } \\
\text { Trust } \\
\text { Leaders should attempt to } \\
\text { maintain trust with their em- } \\
\text { ployees and keep them engaged } \\
\text { throughout the restructuring. }\end{array}$} & $\begin{array}{l}\text { Employee engagement was essential to the } \\
\text { success of an organization. Engagement de- } \\
\text { livers a competitive edge which is essential } \\
\text { during periods of organizational restruc- } \\
\text { ture. When disruptive challenges occur, or- } \\
\text { ganizational congruency and efficacy were } \\
\text { maintained when the workforce remained } \\
\text { engaged. }\end{array}$ & $\begin{array}{l}\text { Burke, Ng, \& Wolpin, } \\
\text { 2015; McManus \& Mos- } \\
\text { ca, 2015 }\end{array}$ \\
\hline & $\begin{array}{l}\text { Organizational change carried out in an en- } \\
\text { vironment of mutual trust, between the orga- } \\
\text { nization and employees, leads to increased } \\
\text { job satisfaction and higher levels of organi- } \\
\text { zational trust. }\end{array}$ & 016 \\
\hline & $\begin{array}{l}\text { High-levels of organizational trust were pos- } \\
\text { itively correlated with improved employee } \\
\text { performance, employee engagement, job } \\
\text { satisfaction and openness to change. }\end{array}$ & $\begin{array}{l}\text { Bowman, Singh, Useem, } \\
\text { \& Bhadury, 1999; Rao \& } \\
\text { Bullayya, } 2017\end{array}$ \\
\hline
\end{tabular}




\begin{tabular}{|c|c|c|}
\hline \multirow[t]{2}{*}{$\begin{array}{l}\text { Organizational Diagnosis } \\
\text { Organizational diagnosis can } \\
\text { result in complete organiza- } \\
\text { tional awareness providing the } \\
\text { bedrock for the restructuring } \\
\text { plan. }\end{array}$} & $\begin{array}{l}\text { Research indicated that organizational diag- } \\
\text { nosis is a necessary first step toward a suc- } \\
\text { cessful organizational change initiative. }\end{array}$ & $\begin{array}{l}\text { Choi, 2011; Lin \& Yoo, } \\
\text { 2013; McFillen, et al., } \\
\text { 2013; Dhillon \& Gupta, } \\
\text { 2015; Hartge, Callahan, } \\
\text { \& King, 2019 }\end{array}$ \\
\hline & $\begin{array}{l}\text { Organizational diagnosis involves collecting } \\
\text { subjective and objective data about the or- } \\
\text { ganization (symptoms), interpreting the data } \\
\text { (systems) to synthesize patterns (standards), } \\
\text { and using the patterns discovered to deter- } \\
\text { mine solutions. Organizational awareness } \\
\text { involves understanding the processes as well } \\
\text { as the weak links in the people, skill sets, } \\
\text { and expectations; the structures and their vi- } \\
\text { ability; and the value proposition. }\end{array}$ & Vakola, 2014 \\
\hline
\end{tabular}

for the organizational culture, structure, and problem. The administrative theory was initially considered because it focuses on organizations from the top down and is commonly used to study military organizations (Stout \& Staton, 2011). This theory is focused more on the structure of the organization and does not pay attention to the needs of the employees. The bureaucratic theory was also considered because it focuses on organizational structure. Max Weber argued that the bureaucratic organization was the best fit for large companies (Krohn, 1971). However, this strategy, while explaining the original competency-aligned structure of the organization, does not address the transformation to a mission-aligned organization.

Ultimately, the contingency theory best addressed the organization's culture and complex restructuring goals focused on aligning the structure with the organization's environment (McKinley \& Scherer, 2000; Mendoza-Walters \& Ivanov, 2016). The new mission-based focus more closely aligns with the organization's mission objectives (internal), as well as the organization's military (external) environment. Contingency theory creates flexibility for managers, providing adaptability to initiate change within the organization's ever-evolving environments (Chenhall, 2003). This is important for an organization's structure and the need for flexibility in prioritizing workloads based on changing mission and resources. A manager's ability to adapt to changes in organizational contingencies was shown to enhance strategies and performance (Karim, Carroll, \& Long, 2016). See Figure 1 for a graphic representation of how the contingency theory applies to the organizational problem.

The star model by Galbraith (2012) was used to establish the contingency theory framework for how the various dimensions of an organization must interface. During an organizational restructure, these dimensions should be evaluated to ensure that they are consistent among themselves and support the organization's strategy and mission.

\section{Discussion}

The research question of how complex organizations can successfully restructure while simultaneously improving the delivery of their products and capabilities was addressed through the lens of the contingency theory. Contingency theory explains how organizations restructure because of changes in their environment. In this case, the organization is adopting an organizational structure that is focused on the mission of the organization, as stated by its customers and higher-level stakeholders. This study was not intended to develop or recommend an organizational structure, but to identify those factors that are important to the success of the restructuring activity. The objective of this study was to explore via a systematic review of the literature the circumstances under which complex organizations can successfully restructure.

The empirical studies from the literature review concurred that organizational leaders have a large part to play in communicating the purpose of the change and the vision of the new organization to the employees. This communication will help build trust and employee engagement as leaders define what is to change and how the change impacts individuals and their work units. Some of this definition can only happen after an organizational diagnosis of the restructuring is done, and job responsibilities are clarified.

While the literature suggested that many organizational restructuring initiatives failed (leading to employee churn, job insecurity, and stress), there are ways to promote success with leaders supporting employees throughout the restructure (Burke et al., 2015). The preparation associated with this transformation is encapsulated in the main elements of the leadership style defined by exploitation and exploration tensions as defined by the ambidextrous leadership style. Attributes of this leadership style produce utility for the organization. As a result, the organization is equipped to maintain capacity and 


\section{Contingency Theory Conceptual Model}

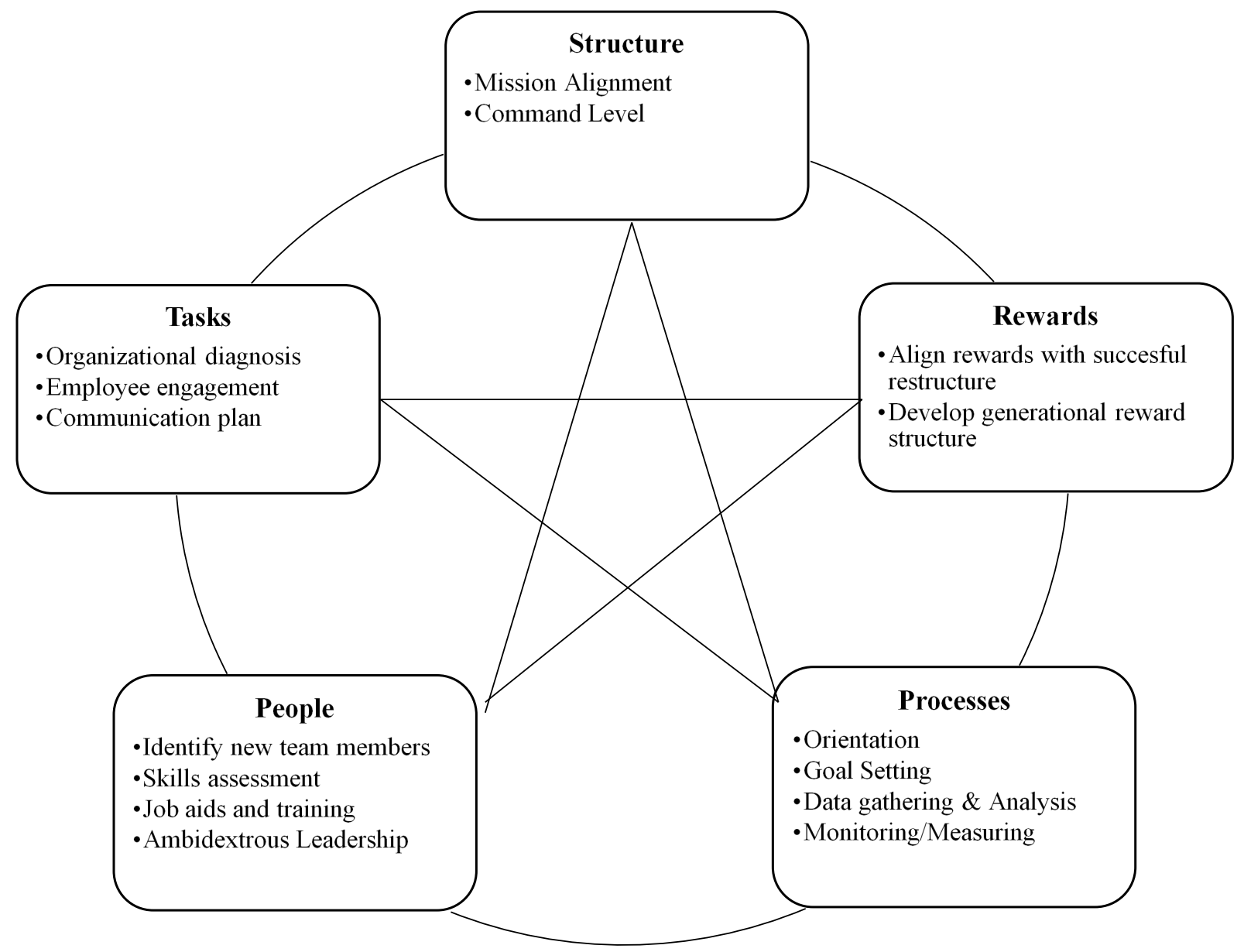

Figure 1. Contingency theory conceptual model for a customer-centric organization. Adapted from “Organizing to Deliver Solutions," by J. R. Galbraith, 2012, Organizational Dynamics, 31, 2, p. 195.

agility while being influenced by external factors. An important aspect for maintaining this agility is based on the ability to evolve into a mature organization. The application of the ambidextrous leadership style was viewed as essential to the success and survival of legacy complex organizations engaged in restructuring. However, in a large complex organization, many leaders are involved in the restructuring. While the study included literature associated with ambidextrous leadership, it would have been enhanced with literature that discussed an ambidextrous organizational culture.

The key findings provided evidence-based solutions as well as recommendations to answer the research question by providing the circumstances in which a complex organization can engage in successful re- structuring. The literature identified some of the underlying causes of restructuring failures, such as loss of employee engagement, job insecurity, and failed communications (Weber et al., 2015). Having identified the risks of restructuring, appropriate recommendations flow from the literature providing clear direction for change. Senior leadership can sponsor successful organizational change through organizational diagnosis and proper planning of job resources and training.

\section{Organizational Diagnosis}

An organizational diagnosis helps in understanding organizational problems by identifying the causes of the problem and selecting appropriate intervention mechanisms (McFillen et al., 2013; Plath, 
2012; Todorović, Komazec, Marič, \& Krivokapić, 2013). Employees' readiness for change should be gauged during this process and on an ongoing basis throughout the restructure (Vakola, 2014). If done well, organizational diagnosis can influence employee readiness for change -- another critical requirement for a successful restructure. The organizational diagnosis requires that management clearly articulate the reasons for the change. This involves understanding the organization's current capabilities and limitations. A third party is recommended to conduct a thorough organizational assessment, which will be shared with stakeholders for approval.

\section{Communications Plan}

An important component of a successful restructure is creating a clear plan for communicating with employees and other stakeholders early, often, and over an extended period (Gupta \& Singla, 2016). Open communication, which includes acknowledging employees' fears and uncertainty surrounding change, is vital to organizational trust and employee engagement (Gupta \& Singla, 2016). The organization should expand its efforts to disseminate the two-way flow of in-

formation regarding restructuring initiatives, ensuring employees and leaders can express questions and concerns regarding changes. It is recommended that the organization introduce the plan with guiding

The leaders are some of the organization's most valuable resources, so it would be prudent to invest in them and make their training and development an ongoing process.

\section{Innovation and Job Satisfaction}

Establishing programs geared toward improving innovation and job satisfaction can produce positive effects on employee engagement and organizational restructuring initiatives (Gupta \& Singla, 2016). Increasing work engagement can increase team innovation, job satisfaction, and improve outcomes during organizational restructuring (Seppälä et al., 2018; Chang, 1996; Domanović \& Janjić, 2018). As a result of the findings, this study recommends implementing job resources structured around improving employee engagement. Job resources are categorized as supportive leadership, job control, and performance feedback. Supportive leadership is a key antecedent of engagement and therefore, an important tool during restructuring (O'Rielly \& Tushman, 2011; Kraft, 2018). Implementing supportive leadership should be a part of leadership training. Job control, which is the ability of the employee to influence their position, was also found to contribute to employee engagement (Seppälä et al., 2018). Employees should be as highly involved as possible in the restructuring of their new job roles and group units, which will provide employees with a sense of control over the organizational change. Performance feedback can also play an important role in creating work engagement (Jonsson \& Scholin, 2013). Organizations should shift performance feedback away from the standard annual review and rating systems and evolve towards more informal conversations with greater frequency and greater emphasis on future development rather than past performance.

\section{Implementation of Recommendations}

Management must clearly articulate the reasons for the change. These reasons should be validated through an organizational assessment by an independent third party. The results of the assessment should then be promptly communicated to all stakeholders. Because employee buy-in is crucial for successful organizational restructuring, management must monitor employee readiness for change periodically (Hemme, Bowers, \& Todd, 2018; Keidel, 1994). This can be done through entity-wide surveys, dissemination of information through communities of practice, and other feedback channels. Management must also create some buffer for unforeseen events during the process of restructure. This flexibility will allow management to overcome unforeseen circumstances during the restructure more effectively. 
Develop a Stakeholder Communication Plan. It is important for the organization to take the initiative to develop an appropriate stakeholder communication plan to ensure clear and transparent communication throughout the restructure. An actionable communications plan should include timelines and resources. The organization will need to set aside appropriate time, technical resources, and funding to implement the recommended plan.

Training and Job Resources. The implementation of the ambidextrous leadership style and job resources can be challenging due to the required level of engagement and the need to successfully manage strategies, which naturally create dynamic capabilities tensions. Successful implementation requires the following foundational elements (O’Reilly \& Tushman, 2011):

1. Clarity around deliverables and metrics

2. The willingness of senior managers to commit resources to exploratory projects

3. Establishment of separate structural units for exploration and exploitation

4. Relentless communication of the new strategy

5. Strategic intent that intellectually justifies the importance of exploration/exploitation

6. Senior management who own the exploration and exploitation unit's strategy

\section{Risks of Implemen- tation}

The strategic implemen-

It is important to understand the risks to implementation, to prepare to overcome the potential hurdles. tation of these foundational elements will generate and establish mission-aligned managerial developmental practicums. It is important to understand the risks to implementation, to prepare to overcome the potential hurdles. Specific threats to implementation are as follows:

1. Organizational leadership needs to understand that implementation can require more time and resources than were initially planned for by the organization.

2. Leadership must be prepared to adjust implementation timelines if necessary, to ensure effective implementation of restructuring initiatives.

3. Tensions during restructuring can cause significant unrest within an organization. Leadership's inability to manage these tensions can sabotage effective change.

4. Lack of consensus could occur within the senior management team.

5. Turnover could occur within the senior leadership team.
6. The locus of integration between the needs of the exploration and exploitation could be either too low or ambiguously defined.

7. It is important to clearly define the integration plan from the beginning of the restructuring to mitigate any potential miscommunication or lack of understanding regarding the change effort.

8. Organizational misdiagnosis is a risk that can be costly to the organization.

9. Extenuating information created by the analysis may preclude current determinations, and adjustments to recommendations may be necessary.

10. And lastly, the biggest risk to implementation is the failure of the restructure efforts to meet their intended objective.

\section{Limitations}

There were several limitations associated with this study. A systematic review was used as the research method as it is intended to offer evidence on a particular topic without introducing researcher bias. Additionally, the scoping review was conducted with four Rapid Evidence Assessments that were then combined for the final review. The scholarly articles were located across a variety of databases, including OneSearch (a university compilation of 45 different library databases), ProQuest, EBSCO, and the Academy of Management website but are by no means exhaustive. The review was limited to scholarly peer-reviewed literature, did not take into account grey literature (non peer-reviewed resources), and did not include snowballing (searching for additional relevant articles using the references of articles) to find additional articles. The process of conducting and combining rapid evidence assessments should have been better standardized on inclusion and exclusion criteria to eliminate reader confusion. Ultimately, the coding and synthesis of the evidence included the final set of 38 articles. The primary findings provided in Table 1 were based on recent literature from 2011-2019, except Bowman, Singh, Useem, and Bhadury (1999). However, Rao and Bullayya (2017) also supported the finding of the importance of trust found in the Bowman et al, 1999 article.

The complexity and size of the organizational issue was a limitation. The target organization is a complex, government organization undergoing a massive restructuring, all while being pushed to increase 
speed and efficiency in the delivery of products and services. The situation, combined with the limited available research on complex, organizational restructuring led to the less relevant available literature.

The research provided us with a focus with regards to implementing a successful restructuring initiative, with an emphasis on keeping employee engagement and an environment based on ambidextrous leadership. However, the literature did not provide specific, actionable documentation that would result in improved delivery of products and services. This lack of information can likely be mitigated by the implementation of the ambidextrous cultural environment, which has been shown to improve performance and innovative outcomes. Also, the organizational diagnosis can help prepare the organization to realign towards a mission focus. One of the best ways to ensure mission success is to know the health of each program, project, or initiative that is advancing the mission. Only then can the organization make the necessary changes to achieve improvements to processes and capabilities.

\section{Conclusions}

Organizations often need to restructure to achieve their strategy and vision. Once organizational leaders have developed a strategy to improve the alignment of the elements of the organization to the mission, a restructure often is required to execute the leader's strategy. In a mature organization, a major restructure can be difficult. The organizational model typically defines the business operation practices for how work is carried out and by whom. The restructure may rebalance human resources by realigning employees and leaders, causing a change in team structures and positional authority. These changes risk a loss of employee engagement if not executed with caution. The goal of this review was to analyze the evidence from the scholarly literature as to how complex organizations can successfully restructure while improving the delivery of products and capabilities.

A systematic review was conducted to understand what actions leaders can take to successfully restructure the organization for better mission alignment. Findings from this study indicate that in today's ever-changing world, organizations need to plan proactively for large organizational change, taking into account organizational diagnosis, employee engagement, training, and job resources. Findings also indicate that leaders can help mitigate restructure failure. This involves leaders being transparent in their communication with employees and other leaders about the reasons for the restructure and the expected benefits. It also involves defining roles clearly and being transparent about changes in job design and job control. Using an ambidextrous leadership approach, leaders may be able to take on the risk of organizational innovation while also identifying efficiencies that lead to the increased speed of capabilities. Ambidextrous leaders can manage employee engagement during the restructure by making employees aware of the need for the restructure and the vision of achieving a balance between the exploration of the new and the exploitation of the current. Despite the hurdles, an organization may successfully implement a new mission-aligned organizational structure and improve the organization's performance through research, preparation, communication, technologies, training, and resources. However, without employee engagement and readiness for change, the organizational challenge of restructuring is great, and could be compounded by leaders who are managing this type of change for the first time. These findings can likely be extended to other complex organizations who want to restructure.

\section{References}

Anderson, H. (2017). What works for you may not work for (gen) me. The Leadership Quarterly, 28(1). 245-260. https://doi.org/10.1016/J.LEAQUA.2016.08.001

ATLAS.ti. (2019). What is ATLAS.ti? Retrieved from https://atlasti.com/product/what-is-atlas-ti/

Bakari, H., Hunjra, A., \& Niazi, G. (2017). How does authentic leadership influence planned organizational change? The role of employees' perception: Integration of theory of planned behavior and Lewin's three step model. Journal of Change Management, 17(2). 155-187. doi:10.1080/14967017.2 017.1299370

Birks, M., Chapman, Y., \& Francis, K. (2008). Memoing in qualitative research: Probing data and processes. Journal of Research in Nursing, 13(1), 6875. doi:10.1177/1744987107081254

Briner, R. B., Denyer, D., \& Rousseau, D. M. (2009). Evidence-based management: Concept cleanup time? Academy of Management Perspectives, 23(4), 19-32. doi:10.5465/amp.23.4.19

Bowman, E. H., Singh, H., Useem, M., \& Bhadury, R. (1999). When does restructuring improve economic performance? California Management Review, 41(2), 33-54. https://doi-org.ezproxy.umuc. $\mathrm{edu} / 10.2307 / 41165985$

Burke, R. J., Ng, E. S. W., \& Wolpin, J. (2015). Economic austerity and healthcare restructuring: Correlates and consequences of nursing job insecurity. The International Journal of Human Resource Management, 26(5), 640-656. doi:10.10 80/09585192.2014.921634 
Chang, S. J. (1996). An evolutionary perspective on diversification and corporate restructuring: Entry, exit, and economic performance during 198189. Strategic Management Journal (John Wiley \& Sons, Inc.), 17(8), 587-611.

Chenhall, R. H. (2003). Management control systems design within its organizational context: Findings from contingency-based research and directions for the future. Accounting, Organizations and Society, 28(2), 127-168. doi:10.1016/S03613682(01)00027-7

Choi, M. (2011). Employees' attitudes toward organizational change: A literature review. Human Resource Management, 50(4), 479-500. Retrieved from https://doi-org.ezproxy.umuc.edu/10.1002/ hrm.20434

Christian, M. S., Garza, A. S., \& Slaughter, J. E. (2011). Work engagement: A quantitative review and test of its relations with task and contextual performance. Personnel Psychology, 64(1).89-136. http://dx.doi.org/10.1111/j.1744$6570.2010 .01203 x$

Dhillon, I. \& Gupta, S. (2015). Organizational restructuring and collaborative Creativity: The case of Microsoft and Sony. The Journal of Business Strategy, 12(1), 53-65.

Domanović, V., \& Janjić, V. (2018). Enterprise efficiency sources in the contemporary business environment. Economic Themes, 56(3), 321-334. Retrieved from http://search.ebscohost.com. ezproxy.umuc.edu/login.aspx?direct=true \&d$\mathrm{b}=\mathrm{bth} \& \mathrm{AN}=133260400$ \&login . asp \&site $=e$ host-live\&scope $=$ site

Galbraith, J. R. (2012), Organizing to deliver solutions. Organizational Dynamics, 31(2). 194-207.

Gibson, A. (2011). Employee engagement at Norfolk county council. Strategic HR Review, 10(3), 27-32.

Gough, D. (2007). Weight of evidence: A framework for the appraisal of the quality and relevance of evidence. Research Papers in Education, 22(2), 213228. https://doi.org/10.1080/02671520701296189

Gough, D., Oliver, S., \& Thomas, J. (2012). Introducing systematic reviews. Sage Publications.

Gupta, S., \& Singla, A. (2016). Organizational change and job satisfaction: An analysis of mediating effect of organizational trust. Indian Journal of Commerce and Management Studies, 7(3), 7. Retrieved from https://search.proquest.com/ docview/1830724664

Hartge, T., Callahan, T., \& King, C. (2019). Leaders' behaviors during radical change processes: Subordinates' perceptions of how well leader behaviors communicate change. International Journal of Business Communication, 56(1), 100-121.
Retrieved from https://doi-org.ezproxy.umuc. edu/10.1177/2329488415605061

Havermans, L., Den Hartog, D., Keegan, A., \& Uhl-Bien, M. (2015). Exploring the role of leadership in enabling contextual ambidexterity. $\mathrm{Hu}$ man Resource Management, 54(1), S179-S200. https://doi.org/10.1002/hrm.21764

Hemme, F., Bowers, M. T., \& Todd, J. S. (2018). Change readiness as fluid trajectories: A longitudinal multiple-case study. Journal of Organizational Change Management, 31(5), 1153-1175. doi:10.1108/JOCM-07-2017-0284

Jonsson, S. \& Scholin, T. (2013). Process of change - competence of development as a restructuring strategy. Journal of Management Development, 35(1), 2-16. doi:10.1108/JMD-11-2013-0146

Karim, S., Carroll, T., \& Long, C. (2016). Delaying change: Examining how industry and managerial turbulence impact structural realignment. Academy of Management Journal, 59(3). 791-817. doi:10.5465/amj.2012.0409

Keidel, R. W. (1994). Rethinking organizational design. Academy of Management Perspectives, 8(4), 12-28. doi:10.5465/ame.1994.9412071698

Kraft, M. (2018). Antecedents and perspectives of ambidextrous leadership. Marketing and Management of Innovations, 4, 5-13. https://doi. org/10.21272/mmi.2018.4-01

Krohn, R. G. (1971). Conflict and function: Some basic issues in bureaucratic theory, 22(2), 115132. doi: $10.2307 / 588206$

Lin, C. \& Yoo, S. (2013). Managers' information seeking behaviors during organizational change: A pre- and post-event analysis. South Asian Journal of Management, 20(4), 7-30. Retrieved from http://search.ebscohost.com.ezproxy.umuc.edu/login.aspx? direct $=$ true $\& d b=b-$ th\&AN $=94350932 \&$ site $=$ eds-live \&scope $=$ site

Mathisen, G. E., Brønnick, K., Arntzen, K. J., \& Bergh, L. I. V. (2017). Identifying and managing psychosocial risks during organizational restructuring: It's what you do and how you do it. Safety Science, 100(Part A), 20-29. doi:10.1016/j. ssci.2016.12.007

McFillen, J., O’Neil, D., Balzer, W., \& Varney, G. (2013). Organizational diagnosis: An evidence-based approach. Journal of Change Management, 13(2), 223-246. Retrieved from https:// doi-org.ezproxy.umuc.edu/10.1080/14697017.20 12.679290

McKinley, W., \& Scherer, A. G. (2000). Some unanticipated consequences of organizational restructuring. Academy of Management Review, 25(4), 735-752. doi:10.5465/AMR.2000.3707703

McManus, J., \& Mosca, J. (2015). Strategies to build trust and improve employee engagement. 
International Journal of Management \& Information Systems, 19(1), 37-42. Retrieved from http://ezproxy.umuc.edu/login?url=https:// search-proquest-com.ezproxy.umuc.edu/ docview/1655539499? accountid=14580

Mendoza-Walters, A., \& Ivanov, S. (2016). Combining passion with planning: Applying organizational theory to improve business operations in non-profit organizations. International Journal of Organizational Innovation, 9(2), 46-51. Retrieved from http://search.ebscohost.com. ezproxy.umuc.edu/login.aspx?direct $=$ true \&d$\mathrm{b}=\mathrm{b}$ th \& $\mathrm{AN}=118454285$ \&login. asp \&site $=e$ host-live\&scope $=$ site

O'Reilly, C. A. \& Tushman, M. L. (2011). Organizational ambidexterity in action: How managers explore and exploit. California Management Review, 53(4): 5-22. Retrieved from https://www.hbs.edu/ faculty/conferences/2015-strategy-research/Documents/Organizational\%20Ambidexterity\%20 in\%20Action.pdf

Pawson, R., Boaz, A., Grayson, L., Long, A., \& Barnes, C. (2003). Types and quality of knowledge in social care. London: SCIE.

Pérez la Rotta, A., \& Campos Herrera, L. (2011). Integral business transformation: A global case study. Industrial and Commercial Training, 43(2), 75-78. doi:10.1108/00197851111108890

Plath, D. (2012). Organizational processes supporting evidence-based practice. Administration in Social Work, 37, 171-188. doi:10.1080/03643107 .2012 .672946

Plimmer, G., Bryson, J., \& Teo, S. T. T. (2017). Opening the black box. Personnel Review, 46(7), 14341451. https://doi-org.ezproxy.umuc.edu/10.1108/ PR-10-2016-0275

Rao, G. V. \& Bullayya, L. (2017). The influence of business restructuring in public sector unit on the relationship between organizational climate, perceived performance and job satisfaction. Academy of Strategic Management Journal, 16(2), 1-12. doi:10.1016/0268-4012(95)00061-5

Rosing, K., Freses, M., \& Bausch, A. (2011). Explaining heterogeneity of the leadership-innovation relationship: ambidextrous leadership. Leadership Quarterly, 22(5), 965-974. Retrieved from https://www.sciencedirect.com/science/article/ pii/S1048984311001160

Seppälä, P., Hakanen, J. J., Tolvanen, A., \& Demerouti, E. (2018). A job resources-based intervention to boost work engagement and team innovativeness during organizational restructuring. Journal of Organizational Change Management, 31(7), 1419-1437. doi:10.1108/JOCM-11-2017-0448

Schaufeli, W., Bakker, A. \& Van Rhenen, W. (2003). How changes in job sickness absenteeism. Journal of Organizational Behavior, 30(7). 893-917. doi:10.1002/job.595

Spremo, T., \& Prodanović, S. (2013). The turnaround strategy and courses of action of companies in the crisis. Zbornik Radova Ekonomskog Fakulteta u Istocnom Sarajevu, (7), 101-111. https://doi-org. ezproxy.umuc.edu/10.7251/ZREFIS1307101S

Stout, M., \& Staton, C. M. (2011). The ontology of process philosophy in Follett's administrative theory, 33(2), 268-292. https://doi.org/10.2753/ ATP1084-1806330206

Sy, T., Horton, C., \& Riggio, R. (2018). Charismatic leadership: Eliciting and channeling follower emotions. Leadership Quarterly, 29 (1), 58-69. https://doi.org/10.1016/j.leaqua.2017.12.008.

Todorović, I., Komazec, S., Marič, M., \& Krivokapić, J. (2013). Cost-effective restructuring based on process approach. Organizacija, 46(4), 157-163. https://doiorg.ezproxy.umuc.edu/10.2478/orga2013-0016

Uhl-Bien, M., \& Arena, M. (2018). Leadership for organizational adaptability: A theoretical synthesis and integrative framework. Leadership Quarterly, 29(1), 89-104. https://doi.org/10.1016/j.leaqa.2017.12.009

Vakola, M. (2014). "What's in there for me? Individual readiness to change and the perceived impact of organizational change." Leadership \& Organization Development Journal, 35(3), 195-209. https://doi.org/10.1108/LODJ-05-2012-0064

Weber, M., Backer, T. E., Orton, K., Barnes, G., Jenkins, W., \& Crecy, C. (2015). Implementing strategic communications planning in a large federal agency. Innovation Journal, 20(3), 1-14. Retrieved from https://www.innovation.cc/scholarly-style/20_3_3_weber_strategic-fed-coms.pdf

\section{Review}

This article was accepted under the strict peer review option. For futher details, see the descriptions at:

http://mumabusinessreview.org/peer-review-options/

Note: The views expressed in this article are those of the authors and do not represent the policy or position of the University of Maryland Global Campus or the Department of Defense. 


\section{Authors}

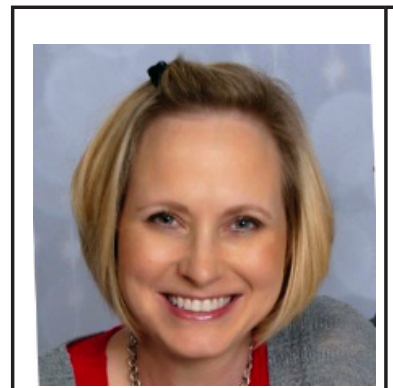

Patty LePage owns a business management consulting company providing startup consulting, business strategy, and marketing to local businesses: https://www. lepagemanagementsolutions.com/. LePage Management Solutions provides customized business solutions for small/medium sized businesses and non-profit organizations including web, business, marketing, and printing solutions. Ms. LePage holds a Bachelor of Science in Psychology, a Masters in Clinical Social Work with a sub-concentration in military social work and is pursuing her Doctorate in Business Administration. She also holds an executive certificate in the Principles of Leading Transformational Nonprofits. With over 25 years of leadership experience, Ms. LePage excels in the areas of business management, customer relations and non-profit leadership.

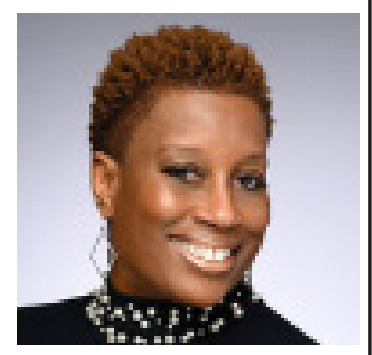

Allyson Oliver-Jones is a dynamic, result-oriented human resource and management professional who offers more than 15 years of experience in all facets of human resource management, recruitment, and employee relations. Allyson's areas of expertise include Pre-employment Screening; Training \& Development; Strategic Planning \& Analysis; Multi-unit Management; Vendor Relationships; Contract Negotiations; Reporting \& Analytics; HR Policy Designing; Productivity Management; Staffing \& Recruitment; Employee Relations; and Problem Solving. She has guided workforces through effective adaptive changes by providing top-caliber staff relations and communications.

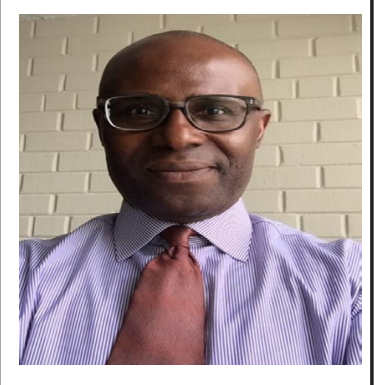

John Onyeaku is a senior auditor in the Office of the Inspector General at a large federal agency in the Washington, DC area. He brings experiences from both the private sector and nonprofit organizations to help achieve his agency's oversight mandate. John believes that a good oversight body helps management achieve its core objectives. John in is a certified auditor as well as a certified fraud examiner. Additionally, John is certified in risk management and governmental auditing. John holds a Bachelor of Science degree from the University of Lagos, Nigeria, and graduate degrees in accounting, international business, management, plus an MBA from universities in New Jersey. He is currently pursuing a Doctor of Business Administration from UMGC.

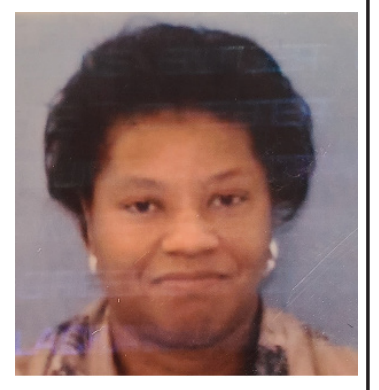

Remedious Bernadine Douglas is an accomplished management consultant. Areas of expertise and interest are leadership competencies, strategic management, risk management, supporting technologies with an emphasis on decision making and problem solving, and communications-motivation-relationship building. She is an adjunct professor, leads Muhlenberg College's Project Management Certificate Program, and is pursuing her Doctor of Management at University of Maryland Global Campus (UMGC). Ms. Douglas holds Master's and Bachelor's of Science degrees in Computer Systems Management-Information Resources Track; and received her Project Management Professional (PMP) certification from the Project Management Institute (PMI).

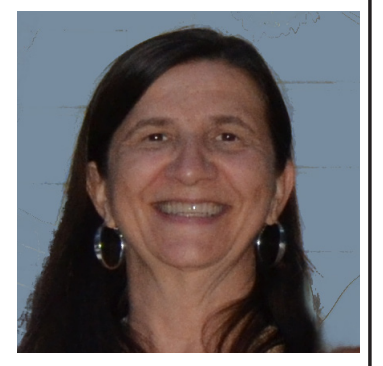

Denise Breckon is Collegiate Faculty at the University of Maryland Global Campus teaching adult professionals to be scholar-practitioners in their fields. After spending 30 years working as an acquisition professional for the Department of Defense, Denise realized that academic research was not findings its way into the management practices - and with a desire to bridge this research-practice gap, she began to teach in the graduate school. Regardless of the course, Denise spends much time igniting her students' passion for research. Denise earned a Bachelor's degree in Electrical Engineering from Penn State and a Masters and Doctorate in Management from the University of Maryland Global Campus. 